\title{
Modeling Generalized Cost of Travel for Rural Bus Users: A Case Study
}

\author{
C. V. Phani Kumar, Debasis Basu, and Bhargab Maitra \\ Department of Civil Engineering, Indian Institute of Technology, \\ Kharagpur, India
}

\begin{abstract}
In order to formulate rational improvement proposal for rural bus services, it is necessary to understand how people value different attributes of travel. In this article, the disutilities of travel have been modeled based on stated choice data collected from trip-makers traveling along a rural bus route in Midnapur district, West Bengal, India. Multinomial Logit Model (MNL) is used to develop utility equations and the total disutility of travel is estimated in the form of generalized cost. The perceived values associated with in-vehicle travel time, service headway, and comfort level for the study route are estimated and found to be significant.
\end{abstract}

\section{Introduction}

Passenger transportation demand in rural India is largely served by the bus transportation system. In India, more than 70 percent of the population is located in rural and suburban areas. The rural population predominantly consists of lowincome households with very low car ownership. Therefore, the rural population is almost completely dependent on the available bus transportation system, creat- 
ing a vital role for rural bus service in the economic growth and development of the country.

Despite ample opportunities for improvement of rural bus transportation in India over several decades, this mode has not drawn adequate attention from transportation professionals and policy-makers. Improvement may be in the form of increase in frequency, comfort level, travel speed etc. However, every possible improvement in existing service is likely to be attributed to an increase in fare level. Therefore, for judicious improvement planning, it is necessary to understand users' perception about various attributes of travel. The objective of this article is to understand rural bus users' perceptions for different attributes of service and model the generalized cost of travel. A typical rural route served by the bus transportation system in India has been considered in the case study.

Many researchers have attempted to model people's perceptions about various attributes using Revealed Preference (RP) and/or Stated Preference (SP) data (Adamowicz et al. 1994; Bates 1982; Kroes and Sheldon 1988; Louviere 1988; Hensher 1994; Jose Holguin-Veras 2002). RP requires a large sample size and cannot accommodate hypothetical alternatives. SP surveys gained importance over RP due to their smaller sample size requirement and their ability to accommodate hypothetical alternatives yet produce results comparable to/on par with RP results (Hunt 2001). Multinomial Logit (MNL) modeling has been widely accepted by researchers and practitioners for analyzing the RP or SP data (Louviere and Woodworth 1983; Jose Holguin-Veras 2002; Hunt 2001). Attributes considered in utility equations, developed by MNL model, have different measuring units. Conversion of these attributes into a common unit enables comparison or estimation of relative importance of each attribute over the other. Summation of these converted attributes is called the generalized cost.

In this article, modeling of generalized cost of travel has been demonstrated with reference to a rural bus route in India, which is connecting a district head quarter (Midnapur) and a tourist place (Digha) in West Bengal, India. The two areas are connected by a direct bus route of $142 \mathrm{~km}$. Travel demand along this route is largely served by ordinary bus service. The bus service takes about 5 hours to cover the distance of $142 \mathrm{~km}$ and serves about 35 intermediate stops.

For the development of utility model, it is necessary to create a database with the help of SP and/or RP observations. Normally, pure SP-based data should be avoided for the development of discrete choice models, as the reliability of parameter 
estimates could be low. However, for the study bus route all users are essentially captive riders and do not have a choice other than accepting the existing bus service. Therefore, for the development of utility model for rural bus users, the database is created based on only SP observations.

Further, there is currently limited information in the literature on stated choice experiments in the context of rural passenger transportation in India or other developing countries. Therefore, before creating a large database for the development of a refined model, a limited number of observations were obtained and analyzed. The utility model developed based on these observations is reported in this article.

\section{Methodology}

\section{Approach}

The SP method, which evolved out of conjoint analysis where attributes are considered jointly, is employed in the present work. Conjoint analysis is an established approach for understanding and predicting consumer trade-offs and choices in marketing research. SP techniques have largely been used in a wide range of disciplines such as transportation (Hensher 1994; Lai and Wong 2000), environmental (Opaluch et al. 1993; Adamowicz et al. 1998), and product marketing (food, home appliances etc.). Most of the SP studies were carried out using traditional rating-based preference techniques (Hunt 2001; Lai and Wong 2000; Praveen and Rao 2002). In rating-based SP studies, numbers (e.g., $1=$ highly preferred, $5=$ highly not preferred) are used to represent the preferences of individuals. These numbers may not represent the actual or true choice behavior of individuals due to the lack of strong theoretical foundation consistent with economics (Adamowicz et al. 1998). As Stated Choice Methods (SCM) have strong theoretical foundation based on economic theory, they are used to model the behavior of individuals. The SCM facilitates estimation of the importance of each attribute from people's responses as they trade off among the alternatives, represented by various attributes and their levels, in the form of choice sets. These methods also facilitate the analysis of how decisions vary with variations in the magnitude of the attributes to model consumer surplus. In this study, different profiles are generated using various attributes with different levels and presented to the respondent in the form of a choice set. Responses in the form of "choices" among the presented choice alternatives are used to estimate the importance of the attributes. 


\section{Theoretical Background}

Random Utility Theory (Thurstone 1927; McFadden 1974), the basis for several models and theories of decision making in psychology and economics, states that the utility of each element consists of an observed (deterministic) component denoted by $V$ and a random (disturbance) component denoted by $\varepsilon$,

$$
\mathrm{U}=\mathrm{V}+\varepsilon
$$

The deterministic part $V$ is again a function of the observed attributes $(z)$ of the choice as faced by the individual, the observed socioeconomic attributes of the individual $(S)$, and a vector of parameters $(\beta)$, then

$$
V=V(z, S, \beta)
$$

A probabilistic statement can be made (due to presence of the random component) as, when an individual " $n$ " is facing a choice set, $C_{n}$, consisting of $J_{n}$ choices, the choice probability of alternative $i$ is equal to the probability that the utility of alternative " $\mathrm{i}$, , $\mathrm{U}_{\mathrm{in}}$, is greater than or equal to the utilities of all other alternatives in the choice set. That is:

$$
\begin{aligned}
& P_{n}(i)=\operatorname{Pr}\left(U_{i n} \geq U_{j n^{\prime}} \text { for all } j € C_{n}\right) \\
& P_{n}(i)=\operatorname{Pr}\left(V_{\text {in }}+\varepsilon_{\text {in }} \geq V_{\text {jn }}+\varepsilon_{\text {in }} \text { for all } j \in C_{n^{\prime}} j \neq i\right)
\end{aligned}
$$

Assuming IID (Gumbel distribution) for $\varepsilon$, the probability that an individual chooses i can be given by the MNL Model (McFadden 1974; Ben-Akiva and Lerman 1985)

$$
P_{i n}=\frac{e^{V_{i n}}}{\sum_{j=j n} e^{v_{j n}}}
$$

The deterministic component of the utility function can be expressed as

$$
V_{\text {in }}=\beta_{1} x_{i n 1}+\beta_{2} x_{i n 2}+\ldots+\beta_{k} x_{i n k}
$$

Where:

$V_{\text {in }}$ is the deterministic component of utility function

$\beta_{1}, \beta_{2}, \ldots, \beta_{n}$. are the parameters associated with attributes

$\mathrm{X}_{\mathrm{in} \jmath}, \mathrm{X}_{\mathrm{in} 2^{\prime} \cdots}, \mathrm{X}_{\mathrm{ink}}$ are the attributes describing the alternative 
Now, let us consider a generalized form of utility equation as follows:

$U=\alpha($ In-vehicle Travel Time $)+\beta($ Travel cost $)+\gamma($ Discomfort Level $)+\varepsilon$

Where:

In-vehicle travel time, travel cost, and discomfort level are the attributes of travel $\alpha, \beta$, and $\gamma$ are the coefficients associated with these attributes

A unit change in the utility value contributed only through change in the invehicle travel time would be caused by changing the in-vehicle travel time by $1 / \alpha$.

The ratio of in-vehicle travel time to the travel cost indicates the value of in-vehicle travel time in monetary terms as perceived by the commuters. Therefore, value of in-vehicle travel time $\left(a_{1}\right)=\alpha / \beta$. Similarly, value of discomfort $\left(a_{2}\right)=\gamma / \beta$.

The Generalized Cost of Travel, summation of the attributes, which are converted into common unit, from origin $i$ to destination $j$ can be expressed in the following form:

$$
C_{i j}=a_{1} t t_{i j}+a_{2}\left(d l_{i j}-1\right)^{*}(t t)_{i j}+F_{i j}+\delta
$$

Where:

$$
\begin{aligned}
& \mathrm{tt}_{\mathrm{ij}} \quad \text { is the in-vehicle travel time between origin } \mathrm{i} \text { and destination } \mathrm{j} \\
& \mathrm{dl}_{\mathrm{ij}} \quad \text { represents the discomfort level experienced } \\
& \mathrm{F}_{\mathrm{ij}} \quad \text { is the direct cost of travel from } \mathrm{i} \text { to } \mathrm{j} \\
& \delta \quad \text { is the modal penalty representing all attributes not included in } \\
& \text { generalized cost (e.g., safety, convenience, reliability etc.) } \\
& a_{1} \quad \text { (i.e., } \alpha / \beta \text { ) and } a_{2} \text { (i.e., } \gamma / \beta \text { ) are weights attached to each disutility. } \\
& \text { They have dimensions appropriate for conversion of all attributes } \\
& \text { to common unit (normally in monitory terms). }
\end{aligned}
$$

\section{Survey Forms}

Survey forms were designed for collecting data related to trip characteristics, respondents' socioeconomic characteristics, and stated preference "choice" from the choice set. During the preliminary investigation it was observed that the journey speeds for buses are considerably low (about $30 \mathrm{kmph}$ ), comfort is less (all the buses are overcrowded for most of the journey period), and the average headway is about 30 minutes. Therefore, attributes such as discomfort, headway, in-vehicle 
travel time, and fare are considered for the preparation of choice sets. Each attribute is further described by three levels. Levels are decided following discussions with experts and trip-makers. Discomfort, a qualitative attribute, is defined and coded on an integer scale (see Table 1).

\section{Table 1. Attribute Discomfort Representation}

\begin{tabular}{|c|c|}
\hline Condition of Travel & DL Value \\
\hline Seating & 1 \\
Standing comfortably & 2 \\
Standing in crowd & 3 \\
\hline
\end{tabular}

The attributes and corresponding levels as used in the study are shown in Table 2.

Table 2. Attributes and Levels

\begin{tabular}{|l|c|c|c|}
\hline Attributes & Level 1 & Level 2 & Level 3 \\
\hline In-vehicle travel time & $-15 \%$ & $-10 \%$ & $-5 \%$ \\
Travel cost & $+5 \%$ & $+10 \%$ & $+15 \%$ \\
Discomfort & Seating & Standing comfortably & Standing in crowd \\
Service headway & $30 \mathrm{~min}$. & $45 \mathrm{~min}$. & $60 \mathrm{~min}$. \\
\hline
\end{tabular}

Fractional factorial orthogonal main effects design is used to produce nine choice alternatives. To reduce the confusion and/or fatigue of respondents, these nine choice alternatives are grouped into three blocks and each respondent is randomly assigned one of the three blocks and asked to choose an alternative.

\section{Database}

The database consists of information related to route, trip, respondent's socioeconomic characteristics, and finally respondent's preference in the form of "choice." Route characteristics include length of the route, number of bus stops, fare structure, and schedule. Trip characteristics are origin, destination, purpose, duration of the trip, and fare paid. Socioeconomic characteristics of the respondent include 
age, gender, education, profession, and income. Preference data is collected in the form of choices where respondents choose an alternative from the three alternatives given in the choice set.

Route characteristics and mode characteristics data are collected from secondary sources such as the Regional Transport Authority (RTA) and transport agencies. Bus stop based interviews are conducted to acquire data related to trip characteristics, socioeconomic characteristics of the respondent, and respondent's stated choice.

\section{Model Development}

During the survey, 180 samples were collected from twelve different locations on the study route. However, only 76 refined samples were used for the development of the utility equation. The SP choice data was coded and fed to LIMDEP 8.0 (2002) for the estimation using MNL (Maximum Likelihood Estimate) models. The discrete choice MNL model was used to analyze the data. Several alternative models were attempted using various combinations and definitions of attribute variables. Finally, the following utility model was selected, based on signs of the coefficients, statistical significance of the coefficients, and predictability of the model. MNL model estimation results are shown in Table 3.

$U=-22.03389(\mathrm{TC})-7.28656(\mathrm{TT})-1.57575(\mathrm{DL})-0.89663(\mathrm{SH})$

Where:

TC equals Travel Cost in rupees per $\mathrm{km}$

TT is in-vehicle travel time in minutes per $\mathrm{km}$

DL represents the Discomfort Level

$\mathrm{SH} \quad$ equals Service Headway in minutes per km length of travel 
Journal of Public Transportation, Vol. 7, No. 2, 2004

\section{Direct Travel Cost}

Based on established fare structure, the direct travel cost model is developed as follows:

$$
\begin{aligned}
& D \geq 4 \mathrm{~km} \text { Direct travel cost }=300 \text { paise } \\
& D>4 \mathrm{~km} \text { Direct travel cost }=300+31(\mathrm{D}-4) \text { paise }
\end{aligned}
$$

Where:

$\mathrm{D}$ is the distance of travel in $\mathrm{km}$

\section{Generalized Cost}

Based on the utility model developed here (Equation 5), the values of different attributes are estimated as follows:

$$
\begin{aligned}
& \text { Value of In-vehicle travel time } \quad=7.28656 / 22.03389 \\
& =0.33 \text { rupees per minute } \\
& =33 \text { paise per minute } \\
& \text { Value of in Service Headway } \quad=0.89663 / 22.03389 \\
& =0.0406 \text { rupees per minute } \\
& =4.06 \text { paise per minute } \\
& \text { Value of discomfort } \quad=1.57575 / 22.03389 \\
& =0.0715 \text { rupees per unit DL per } \mathrm{km} \\
& =7.15 \text { paise per unit } \mathrm{DL} \text { per } \mathrm{km} \text {. } \\
& \text { Generalized Cost (in paise) } \quad=33 \text { (In-vehicle travel time in minutes) } \\
& +4.06 \text { (headway in minutes) } \\
& +7.15 \text { (Existing DL }-1) * \text { (Travel distance in kilometers) } \\
& \text { + Direct Travel Cost }
\end{aligned}
$$

\section{Results and Discussions}

From Table 3, it can be seen signs of the parameter estimates are as expected and in agreement with the actual condition of the study route. It is evident from the $t$ ratios that the parameter estimates are statistically significantly different from zero as absolute t-ratios of all the parameters are greater than 1.96 (Louviere et al. 2000) 
except for cost attribute. The overall goodness of fit is considered using Pseudo $R^{2}$ ( $R$-squared). Value of the pseudo $R^{2}$ between 0.2 and 0.4 indicates acceptable model fit (Louviere et al. 2000).

Table 3. MNL Model Estimation Results

\begin{tabular}{|l|c|c|}
\hline Attribute & Coefficient & Abs.t-ratio \\
\hline Cost & -22.03389 & 1.226 \\
\hline In-vehicle Travel Time & -7.28656 & 3.133 \\
\hline Discomfort & -1.57575 & 4.278 \\
\hline Service Headway & -0.89663 & 2.386 \\
\hline Number of samples = 76 & \\
\hline Log likelihood function $=-59.45$ & \\
\hline Log-L[L(0)] = -79.03 & \\
\hline R-squared $=0.2478$ &
\end{tabular}

The ratio of the parameter estimate for in-vehicle travel time over parameter estimate for travel cost, 33 paise per minute, is the estimated value of in-vehicle travel time. Similarly, the ratio of parameter estimate for discomfort over parameter estimate for travel cost, 7.15 paise per unit $\mathrm{DL}$ per $\mathrm{km}$, is the estimated value of a unit change in discomfort level per kilometer of travel. The values of in-vehicle travel time and discomfort level, as obtained from the present study reflect the extremely poor operating conditions of the existing bus service along the study route. The ratio of parameter estimate for in-vehicle travel time over parameter estimate for discomfort is 4.6. This indicates that in-vehicle travel time is four and half times as important as travel comfort. Similarly, the ratio of parameter estimate for service headway over parameter estimate for discomfort is 0.56 , which indicates that the service headway is 56 percent as important as comfort. These two observations suggest that the existing comfort level in the services is poorer than what people expect it to be. The ratio of parameter estimate for service headway over parameter estimate for in-vehicle travel time is 0.12 . This indicates that the service headway is only 12 percent as important as in-vehicle travel time.

The modeled value associated with in-vehicle travel time is much higher as compared to the values associated with other attributes of travel. The higher value associated with in-vehicle travel time is primarily due to overcrowding inside the buses laced with longer journey time offered by the existing bus service. However, 
the modeled values associated with different attributes of travel are perceived values obtained from SP experiments and they are, therefore, influenced by the existing service attributes. A comparison of the values of in-vehicle travel time and service headway indicates that user preference is more on reduction of in-vehicle travel time rather than improving the service headway. Further, as rural bus users normally plan their trips based on existing schedule, the waiting time is much less than the service headway. Accordingly, the perceived value of waiting time will be higher than the value of service headway.

The values associated with different attributes of travel, as obtained from the present work, are also compared with the findings reported in literature. The value of in-vehicle travel time and discomfort level as reported for Mumbai were 21 paise per minute ( 13.2 rupees per hour) and 4.5 paise per minute ( 7.5 rupees per hour) per unit change in discomfort level, respectively (Mumbai Metro Planning Group 1997). Although these values are for urban public transport users corresponding to the year 1997, they are generally in agreement with the values obtained from the present work. The value of journey time was reported as $42 \mathrm{NOK}$ (. Indian rupees 250) per hour for public transport users in Akershus, Norway (Nossum 2003). In Australia, a study of high speed rail indicated that the value of door-to-door travel time savings ranged from $\$ 36$ (. Indian rupees 1170) per hour for discount economy travel to $\$ 59$ (. Indian rupees 1920) per hour for full economy travel for air business market and a line haul time value as $\$ 10.86$ (. Indian rupees 350) per hour for the car nonbusiness market (Hensher 1997). A study of the Cleveland-Columbus-Cincinnati High Speed Rail service showed the value of travel time as $\$ 12$ (. Indian rupees 530) per hour and $\$ 4$ (. Indian rupees 170) per hour as the value of frequency for bus nonbusiness trip-makers (Transportation Economics \& Management Systems 2001).

In general, there is wide variation of the values associated with travel time. The value of travel time is controlled by socioeconomic characteristics of users: in rural India, it is predominantly low-income people with negligible car ownerships; in urban areas, it is a mix of low- to high-income people with higher levels of car ownership. Again, the socioeconomic characteristics of public transport users in developed and developing countries are different. Therefore, the values associated with different attributes of travel in devloped and developing countries are also found to be different. The perceived values associated with different attributes of travel for rural bus users in India is much lower than the values reported in devel- 
oped countries predominantly due to the difference in socioeconomic characteristics.

\section{Conclusions}

To formulate rational improvement strategy for bus transportation in rural India, it is essential to understand how users value different attributes of travel. There is currently limited information available in literature about the values associated with different attributes of travel for rural bus users in developing countries such as India. In the present research, a choice-based conjoint analysis method has been applied for modeling the values associated with different attributes of travel with reference to a typical rural bus route in India. This research found that the stated preference data are effective for developing a utility model comprising different attributes of travel, even in a nonurban scenario. Responses obtained from nonurban trip-makers in the form of choice are consistent and encouraging. Based on the utility equation, values of in-vehicle travel time, service headway, and comfort level are estimated. Finally, the generalized cost model was developed with reference to the study route. The estimated values associated with in-vehicle travel time, comfort, and headway of service are found to be significant and in agreement with the actual condition of the study route. Therefore, all these attributes should be considered while formulating improvement proposals for rural public transportation systems.

The values associated with different attributes of travel depend on socioeconomic characteristics of users. The modeled values obtained in the present work are generally in agreement with the limited findings available in India. However, the modeled values are much lower than the findings reported in literature for developed countries. This is because rural bus users in India are predominantly lowincome people. The number of observations used in the present work is limited and the model presented is also an initial attempt. Further works are necessary to refine the model based on additional data and apply the knowledge for improving the bus transportation in rural India.

\section{Acknowledgments}

The work presented in this article is based on a research project sponsored by the Department of Science and Technology (DST), Ministry of Science and Technology, Government of India. 
Journal of Public Transportation, Vol. 7, No. 2, 2004

\section{References}

Adamowicz, W. L., J. Louviere, and M. Williams. 1994. Combining stated and revealed preference methods for valuing environmental amenities. Journal of Environmental Economics and Management. 26: 271-292.

Adamowicz, W., J. Louviere, and J. Swait. 1998. Introduction to attribute-based stated choice methods. Final Report submitted to National Oceanic and Atmospheric Administration, U.S. Department of Commerce.

Ase Nossum, 2003. Public transport: Traveller's valuation of time in the Oslo region. Nordic Road \& Transport Research (2).

Bates, J. 1982. Stated preference technique for the analysis of transportation behavior. In Proceedings of World Conference of Transportation Research, Hamburg, W. Germany, pp. 252-265.

Ben-Akiva, M., and S. R. Lerman. 1985. Discrete choice analysis: Theory and applications to travel demand. Cambridge: MIT Press.

Hensher, D. A. 1994. Stated preference analysis of travel choices: The state of practice. Transportation 21(2): 107-133.

Hensher A. David. 1997 A practical approach to identifying the market potential for high speed rail: A case study in the Sydney-Canberra Corridor. Transportation Research-A 31 (6): 431-446.

Hunt, J. D. 2001. A stated preference analysis of sensitivities to elements of transportation and urban form. Paper presented at the 80th Annual Meeting of the Transportation Research Board.

Louviere, J. J., D. A. Hensher, D. S. Joffre. 2000. Stated choice methods. Analysis and applications. Cambridge University Press.

Jose Holguin-Veras, P. E. 2002. Revealed preference analysis of commercial vehicle choice process. Journal of Transportation Engineering 128 (4): 236-346.

Lai, K., and W. Wong. 2000. SP approach toward driver comprehension of message formats on VMS. Journal of Transportation Engineering 126(3): 221-227.

Kroes, E. P., and R. J. Sheldon. 1988. Stated preference methods: An introduction. Journal of Transport Economics and Policy 22: 11-25.

LIMDEP 8.0 Reference Guide. 2002. Econometrics Software Inc. 
Louviere, J., and G. Woodworth. 1983. Design and analysis of simulated consumer choice for allocation experiments. Journal of Marketing Research 20(4): 350367.

Louviere, J. J. 1988. Conjoint analysis modeling of stated preferences: A review of theory, methods, recent developments and external validity. Journal of Transport Economics and Policy 22(1): 93-119.

McFadden, D. 1974. Conditional logit analysis of qualitative choice behavior. In P. Zarembka (ed.), Frontiers in econometrics. New York: Academic Press, 105142.

Mumbai Metro Planning Group (MMPG). 1997. Mumbai metro study: Travel demand forecasting model. Working Paper No. 4, Mumbai.

Opaluch, J. J., S. Swallow, T. Weaver, C. Wessels, and D. Wichlens, D. 1993. Evaluating impacts from noxious waste facilities: Including public preferences in current siting mechanisms. Journal of Environmental Economics and Management 24:41-59.

Praveen, K. S., and K. V. K. Rao. 2002. Estimation of passenger demand on a proposed passenger water transport system. Proceedings of Transportation Planning and Methodologies for Developing Countries, IITBombay, Mumbai.

Thurstone, L. L. 1927. A law of comparative judgment. Psychological Review 4: 273-286.

Transportation Economics \& Management Systems (TEMS) Inc. 2001. ClevelandColumbus-Cincinnati High Speed Rail Study. Final Report. Prepared for Ohio Rail Development Commission. 


\section{About the Authors}

C.V Phanı Kumar (phani@civil.iitkgp.ernet.in) is a research scholar in transportation engineering, Department of Civil Engineering at Indian Institute of Technology Kharagpur, India. His research interests include transport planning and framing-related policy issues using behavioral analysis. He has experience in geometric design of highways and traffic engineering.

Debasis BAsu (dbasu@civil.iitkgp.ernet.in) is a research scholar in transportation engineering, Department of Civil Engineering at Indian Institute of Technology. His research interests include application of ANN in traffic parameters modeling, travel demand modeling, using behavioral analysis in transport planning and policy issues, congestion relieving, and improving traffic flow.

BharGaB Maltra (bhargab@civil.iitkgp.ernet.in) obtained his Ph.D from IIT, Bombay, India, and is presently an assistant professor in transportation engineering, Department of Civil Engineering at Indian Institute of Technology. His research interests include traffic management, operation and maintenance, congestion modeling, and improving public transport systems using behavioral analysis. He has published numerous papers in both national and international journals. 